\title{
THE FIRST REPORT OF \\ THE DEPARTMENTAL COMMITTEE APPOINTED TO INQUIRE INTO THE VENTILATION OF FACTORIES AND WORKSHOPS.*
}

\author{
BY JAMES WHEATLEY, M.D., D.P.H., \\ Medical Officer of Health for the County of Salop.
}

I AM pleased to have this opportunity of saying a few words on a report which, in my opinion, makes one of the most important suggestions made by any Departmental Committee or Royal Commission of recent years. The importance of this report will be understood when it is appreciated that it is an attempt to secure a better air for nearly $5,000,000$ of workers in the factories and workshops of the United Kingdom. Its importance, in another sense, will be brought home to us particularly when we grasp the fact that the carrying out of these recommendations will cause a great deterioration in the atmospheric conditions in which more than 100,000 operatives in this distriet work.

The report contains a mass of interesting and useful information, but I propose to confine my remarks to two points:

1. Is the amount of carbonic acid the best measure of ventilation?

2. Is the limit recommended by the Committee a suitable one?

I think we shall all agree, if the difficulties of administration can pe overcome, that a carbonic acid standard is the proper test of efficient ventilation. There is no other scientific method of measuring ventilation, nor is there any other method that is universally applicable. In a room mechanically ventilated one can measure the air entering or leaving, or both; but it is impossible to do so in a room naturally ventilated. This measurement, too, does not take into account the diffusion of the fresh air, which may be very imperfect. On the other hand, the amount of carbonic acid present is a sure indication of the fresh air supply and its diffusion.

Is the standard suggested a good one?

It is not quite apparent at first sight what the standard really is. In the first recommendation of the report the limit of 12 volumes per 10,000 is suggested for the period when gas is not burning. In the third recommendation it is stated that proceedings should not be taken unless there is an average in two or more parts of the room of 13 volumes. The real limit, then, is an average of

\footnotetext{
* Paper read to open discussion at a meeting of the North-Western Branch of the Society, February 20th, 1903.
} 
13 volumes, or what is equal probably to a maximum of at least 14 volumes. There is much to be said against this principle of averaging health conditions. If a man in one corner of a room is working under bad conditions, it is very little consolation to him to know that the general average is good. The limit, then, that is suggested is for all practical purposes equal to a maximum of 14 volumes per 10,000 . Let us compare this for a moment with the standard of 9 volumes which is the legal limit in humidified weaving sheds. Assuming that 4 volumes is the usual amount of carbonic acid in the air of towns, an excess of 5 volumes is allowed in weaving sheds. With a maximum of 14 volumes an excess of 10 volumes would be allowed. In other words, if the recommendations of this Committee are put into force, there will be a relaxation of the law relating to humidified weaving sheds allowing double the amount of respiratory impurity that is permitted at present. One should always require very strong proof that a sanitary standard is impracticable before it is lowered, however little; but the proof should be most convincing before a standard is lowered, as in the present proposal. by 100 per cent. As far as I can see, this very retrograde suggestion has been made without any facts being adduced to justify it. On the other hand, much evidence can be produced from the report itself to show that the present standard is a good workable one. The average of all the observations made by the Committee during daylight in humidified sheds was only $7 \cdot 8$, and many of these sheds had not been specially ventilated to meet the requirements of the 1898 Order. I would refer you in this connection to Dr. Ransome's letter in Public Healtr of February. It contains figures, from the Committee's report, relating to factories that are said to be fair samples in respect of ventilation. The average of these figures is $6 \cdot 5$. So far, then, as their own analyses of the air of humidified weaving sheds are concerned, there is absolutely no evidence in favour of lowering the standard, and it must be remembered that these are the only factories in which any attempt has been made to come within a prescribed standard. Observations upon other factories are for this object practically useless. The Committee state that the standard of 9 volumes is somewhat stringent. There happens to be a very practical method of testing whether or not it is so stringent as to be oppressive. A manufacturer by ceasing steaming can escape this regulation. Instead of the number of humidified sheds decreasing, there has been an increase of about 10 per cent. since this standard of 9 volumes was fixed. What clearer evidence can one have that this standard is not really oppressive? 
If it is proved, as I hold it is, that the standard of 9 volumes in 10,000 is a good one for weaving sheds, it is also the correct one for all places where power is available-i.e., for all factories. The Committee seems to have been under some misapprehension as to how the standard of carbonic acid should really be applied. None of us, I am sure, would suggest that the occupier of a factory should be punished, because the air of his factory happened to contain at the time of observation more carbonic acid than the standard, in the same manner as a milk-seller would be punished for adulterating his milk. Such a state of things would be most oppressive and anreasonable. What is required is that it should be the duty of the employer to provide means of ventilation which shall under ordinary conditions secure the legal standard. These means of ventilation, having been approved by the inspector as securing the standard, the only obligation of the employer is to see that they are properly maintained in good working order. The inspection, too, being devoted to seeing that the means of ventilation which have been once approved are properly maintained, would be much simplified. This was practically the recommendation of the Roscoe Committee, and if it had been embodied in the report under consideration there would have been no necessity, according to the Committee's own showing, to have recommended a higher standard than 10 volumes. This is borne out by the following quotation from p. 4 of the report: "From our own observations we have come to the conclusion that it is reasonable to expect that under ordinary circumstances 10 volumes should not be exceeded in factories and workshops unless gas is burning."

I have dealt hitherto entirely with factories because I felt that here we were on tried ground. My own investigations into the air of workshops having been made several years ago, and not having been devoted specially to solving the problem before us, I prefer to leave this matter to be dealt with by subsequent speakers. In workshops the difficulties of consistent ventilation, and consequently the difficulties in the way of adopting a carbonic acid standard, are certainly greater. It is very evident that the desire to recommend one uniform standard for factories and workshops influenced the Committee greatly in fixing what must be considered such a low standard for factories. A higher standard of ventilation is practicable in factories than in workshops, on account of the available mechanical power. To quote from p. 112 of the report: "Ventilation by fans has the great advantages that (1) practically unlimited quantities of air can be supplied; (2) the supply is completely under control, so that it can be relied upon." It is necessary, then, to adopt one 
of three courses: (1) To have separate standards of ventilation for factories and workshops; (2) to level the ventilation of factories down to what can be attained in workshops; (3) to level the ventilation of workshops up to what can be attained in factories, and insist upon the use of mechanical power where necessary. The first course is, to my mind, at the present time the best practicable one. That the second course, which appears to be the one adopted by the Committee, is not desirable is also supported by the fact that there are four million people employed in the factories of the United Kingdom, and, according to the returns, only about three-quarters of a million in the workshops, and that the tendency is for factory employment to increase and workshop employment to decrease. I do not contend that it is not as important to ventilate workshops as factories, although there are often conditions of heat and dust, and conditions due to aggregation of large numbers in factories, that are not often present in workshops, but simply that a higher standard of ventilation is practicable in factories than in workshops.

There are many other very important and interesting matters which time does not permit me to dwell upon-e.g., (1) the standard adopted for the time when gas is burning, which I think would have the most beneficial effect of abolishing the naked gas flame; (2) the accuracy of the apparatus suggested-a most important matter, because the practicability of adopting a standard depends upon the possession of a ready means of testing the air ; (3) the question as to whether any order based upon this report would be carried out by the sanitary authorities or by the factory inspectors. Before closing my remarks, I wish to put before you a resolution that $I$ intend to propose at the end of the meeting. I put it forward now in order that subsequent speakers may discuss it:

"That this Branch would welcome the adoption of a standard of ventilation for factories based upon the carbonic acid in the air, but they would strongly urge that the standard of purity be that at present fixed for humidified cotton-cloth factories."

\section{DISCUSSION.}

Dr. Wruliamson considered the estimation of the amount of carbonic acid in the air of factories and workshops to be the best method of determining the sufficiency of ventilation in these places, and in the smaller workshops to be the only method which could be adopted with any degree of accuracy. It would be impossible to measure the amount of air going in or out of these rooms. The suggestion of raising the amount of carbonic acid allowable in factories 
above the standard already fixed for those buildings in which the air is humidified was a matter of surprise. If it had been found possible, without any great difficulty, to keep the amount of carbonic acid below 9 parts in 10,000 in those buildings where the air contains a considerable amount of moisture, and thus does not circulate so freely, it ought to be possible to keep down to this standard where steam is not employed. In looking through the report it was noticeable that in several country workshops, where there ought to be no necessity for overcrowding, the amount of carbonic acid in the rooms was higher than in similar places in the more thickly populated Metropolis, this result being evidently due to inattention to the necessity for proper ventilation. As regards the high allowance of carbonic acid in rooms when gas was being burned, an improvement in the room atmosphere was often experienced when the gas was lighted if the burners were fixed beneath a proper outlet for the products of combustion. Not only are the fumes from the gas conveyed into the open air by these outlets, but the hot air acts as an extractor of the foul air of the room, and in consequence better ventilation is the result. He supported Dr. Wheatley's resolution strongly.

Dr. John RoBkrTson (Sheffield) regretted that the medical profession had not been represented on the Departmental Committee appointed to go into this question. To his mind the best way in which to have solved the question would have been to have taken certain factories and tested the air in them, then fitted them with proper ventilating appliances, and after these had been in working order for some time, tested the air again. It would probably have been found then that the limit fixed was far too high. He observed that the factory inspector was to be the authority for testing the air in factories, and as regards workshops he would suggest that it be left to the sanitary authorities. Legislation was at present somewhat mixed in connection with workshops, the heating of workshops being in the factory inspector's hands, and the ventilation in the hands of the sanitary authorities.

Dr. Greknwood (Blackburn) stated that in his short experience the limit fixed for humidified weaving-sheds worked well, and, so far as he could judge, the health of the workers had appeared to improve. Some kinds of cloth were improved in production and in quality. $\mathrm{He}$ had heard that the accuracy of the apparatus described in the report was questionable.

Dr. Meredith Young stated that in the appendices to the report several important fallacies on the question of ventilation had been exposed, and some of the difficulties of working ventilating appliances, notably fans, had been explained. In his opinion it would be a good thing if manufacturers could be made acquainted with some of the practical points contained in the report, for they could not be expected to worry them out of a blue-book for themselves. He suggested that, if possible, a standard should be fixed for the amount of carbonic acid to be allowed for gas-consumption, so much per burner or per jet.

Dr. Francis VAcher, Dr. Berry, and others continued the discussion.

Dr. Wheatley's resolution was then put, and was carried unanimously.

The Branch wishea that the reasons for the resolution be forwarded with the resolution to the Secretary of the Society.

The following reasons were adduced in favour of the resolution : 
1. The analyses made by the Committee show clearly that a standard of 9 per 10,000 is already not exceeded in a large proportion of factories.

2. The average of all the observations made during daylight in humidified cotton-weaving sheds was only $7 \cdot 8$ per 1,000 . It must be remembered that these are the only factories in which an attempt has been made to come within a required standard.

3. The standard of 9 per 10,000 has worked successfully in cottonweaving sheds.

4. The average of several analyses of air from factories which were said by the Committee to be fair samples of ventilation was only 6.5 (see Dr. Ransome's letter in Public Health).

5 . An average in a room of 13 parts of carbonic acid per 10,000, which is the standard adopted by the Committee, would indicate very inefficient ventilation, and it is doubtful whether such a standard would be any help in our efforts to obtain improved ventilation.

Fuies in BakeHouses.-The Health Department of Buffalo has found (Mun. Journ, and Engineer, December, 1902) that many bakeries are operated in such an uncleanly manner as to endanger public health. The rooms in which the baking is done are filthy. Windows are left open so that germs can blow in from the streets. Flies are allowed to contaminate cake and bread, and the rules of health that should be obeyed in every shop of this character are ignored. Inspection showed that, while most of the bakers were particular about the cleanliness of utensils, no attention was paid to the flies. The bakers will be ordered to put in screens, or else be arrested.

Cubic Space in Bakerouses.-The secretary of the National Association of Master Bakers and Confectioners has received the following letter, dated January 27 th, from the Home Office:

"I am directed by the Secretary of State to inform you that he has under his consideration a proposal, which is supported by the Society of Medical Officers of Health, that he should make an order, under Section 3 (2) of the Factory and Workshops Act, 1901, increasing the standard of cubic space per worker in bakehouses of all classes from the 250 cubic feet preseribed by Section $3(1)$ of the Act to a minimum of 500 cubic feet. The reasons urged on behalf of this proposal are, briefly, the laborious work carried on in bakehouses, the high temperature maintained, the fact that little ventilation takes place (the work being carried on in many cases continuously by night and day shifts of men), and that the air is in consequence impure, and the difficulty of devising and maintaining proper ventilation. To these may be added the general use of gaslight in bakehouses, the evolution of fermentation products in baking, and the evolution of steam, etc., when a batch of bread is withdrawn. Before arriving at a decision on this matter the Secretary of State will be ready to hear any representation which the Association of Master Bakera may wish to make. He would be glad to receive any such representation with as little delay as is practicable, since it would be convenient that any order made on the subject should come into force at the same time as the provisions in Section 101 of the Factory and Workshops Act as to underground bakehouses.--I am, etc., Henky Cunninghame." 